\title{
A narrative review of biosimilars: a continued journey from the scientific evidence to practice implementation
}

\author{
Jorge J. García ${ }^{1}$, Luis E. Raez ${ }^{2}$, Daniel Rosas ${ }^{3} \wedge$ \\ ${ }^{1}$ Oncology Services, Baptist Health South Florida, Miami, FL, USA; ${ }^{2}$ Thoracic Oncology Program, Memorial Cancer Institute/Memorial Health \\ Care System, Florida International University (FIU), Miami, FL, USA; ${ }^{3}$ University of Texas Health Science Center at San Antonio, Internal \\ Medicine Department, San Antonio, TX, USA \\ Contributions: (I) Conception and design: All authors; (II) Administrative support: All authors; (III) Provision of study materials or patients: All \\ authors; (IV) Collection and assembly of data: All authors; (V) Data analysis and interpretation: All authors; (VI) Manuscript writing: All authors; (VII) \\ Final approval of manuscript: All authors. \\ Correspondence to: Daniel Rosas, MD. University of Texas Health Science Center at San Antonio, Internal Medicine Residency Department, San \\ Antonio, TX, USA. Email: rosasd1@uthscsa.edu.
}

\begin{abstract}
Biologic agents have revolutionized the management of serious health conditions in the last two decades. The use of "targeted therapy" brings not only better progression free survivals and overall survivals, but also better toxicity profiles and quality of life benefits, compared to empirical palliative chemotherapy. However, given the high cost associated with biologic drugs and the sharp increases in biologic drug utilization, this drug category has significantly raised healthcare cost over the years. A similar phenomenon was previously experienced with branded simple chemical compound drugs, including chemotherapeutic agents, which was largely mitigated by the introduction of a generic approval pathway, decreasing the costs of the drugs, making them more affordable, given to the increase in competition among the drug makers. A similar opportunity presents years later with the completion of the full patent exclusivity period of many biologics. However, the ending of patent exclusivity, although enables more market competition, does not guarantee market penetration. Stakeholders, such as patients, providers and payers, must build trust and confidence in the science of biosimilars and the product specific studies leading to FDA approval in order to incorporate these products to practice and enable the biosimilar market at large to reach the potential to significantly contribute to reductions in drug cost. Dissemination of scientific and emerging biosimilar evidence is paramount in order to support stakeholder informed decision making and enable each to benefit from expanded treatment options. This paper describes the biosimilar development, approval process, and reviews a number of challenges with the marketing implementation of biosimilars.
\end{abstract}

Keywords: Biosimilars; interchangeability; extrapolation; immunogenicity

Submitted Apr 24, 2020. Accepted for publication Aug 03, 2020.

doi: $10.21037 /$ tlcr-20-601

View this article at: http://dx.doi.org/10.21037/tlcr-20-601

^ ORCID: Luis E. Raez, 0000-0003-2669-5771; Daniel Rosas, 0000-0001-8909-5760 


\section{Introduction}

The simplest forms of biologic drugs entered the U.S. market in the 1970s and primarily consisted of blood products and vaccines. The rise of cloning and gene expression technology enabled biosynthesis of genetically modified organisms, which allowed the production of increasingly complex biologic molecules, including Genentech's recombinant human insulin in 1982, the first FDA-approved monoclonal antibody and the entry of recombinant monoclonal antibodies in cancer treatment in 1997 (1). Biologics, also known as therapeutic proteins, are medications produced in a laboratory to mimic natural proteins. This biologics mimic or antagonize a natural proteins function (2). Since then, biologics have revolutionized the treatment of serious medical conditions in the U.S. However, the high cost associated with biologic therapies along with increasing biologic utilization over the years have led to sharp increases in the overall healthcare cost curve (3). Table 1 provides a list of contributing factors as it relates to the increase of biologics utilization. We present the following article in accordance with the Narrative Review reporting checklist (available at http:// dx.doi.org/10.21037/tlcr-20-601).

Overall drug cost remains a top public concern in the U.S.; biologics add up to the highest drug cost by category nowadays. A similar phenomenon took place in the U.S. in 1980s as drug cost associated with branded, synthetic products reached record highs, leading to the "Drug Price Competition and Patent Term Restoration Act of 1984," also known as the "Hatch-Waxman Amendment", which established an approval pathway for generic drugs. This Act enabled an avenue for generic drugs competition, becoming one of the most impactful cost savings interventions in the U.S. healthcare system to date (3). However, the HatchWaxman Amendment did not provide the appropriate regulatory framework to support approval of biosimilars.

Generic drugs are developed by following multistep chemical synthesis yielding exact molecular copies of the brand compound. The generic drugs approval process is based on pharmaceutical equivalence and human bioequivalence. Biosimilars are biologic agents that are not chemically identical, but are highly similar to an approved reference biologic, notwithstanding minor differences in clinically inactive components and with no meaningful differences in efficacy, safety and purity (4-6).

The Public Health Service Act was amended in 2009 to include the "Biologic Price Competition and Innovation
(BPCI) Act", also referred to as the "351(k) approval pathway", which created an avenue for abbreviated licensure pathways for demonstrating biosimilarity or interchangeability with FDA-licensed biologics (4). It is of important distinction to note that the goal of the 351(k) pathway is not to reestablish primary safety and efficacy of biologic compound-as that has already been established by the innovator company-but rather to demonstrate product is highly similar to reference biologic. This FDA abbreviated approval pathway is mainstay to the developers' ability to bring biosimilars to market at the lowest viable cost (7).

\section{Biosimilars development and approval process}

Biosimilars are manufactured following reverse-engineering, in other words, by starting with the final therapeutic protein of interest and working the synthesis steps backwards (8). Biosimilars, like other biologics, come from living systems (e.g., bacteria and yeast) and for that reason, it is essentially impossible to consistently produce an identical copy of biologic drugs. Even batches of the same reference product that are produced within the same manufacturing plant and with the use of the same cell line may be dissimilar. Different steps in the manufacturing process can lead to molecular differences in clinically inactive components of the drug. Examples include post-translational protein modifications (alterations to the $\mathrm{C}$ or $\mathrm{N}$ terminals) and glycosylation; a process by which sugar residues are attached to the amino acid chain bearing amino or hydroxyl groups. Biosimilars can also differ in $3 \mathrm{D}$ structure, isoform profiles and protein aggregation, compared to the reference biologic. These resulting variations are demonstrated to not be clinically meaningful in terms of efficacy and safety during the development and approval process. The FDA requires pharmacodynamic (PD), pharmacokinetic (PK) and immunogenicity studies to demonstrate biosimilarity $(5,6,9)$. However, in every case, biosimilars are required to have identical therapeutic amino acid sequence relative to the reference product.

The ultimate goal of the biosimilar development and approval process is to demonstrate biosimilarity; not to reestablish primary efficacy and safety already proven by the innovator company. Unlike the development pathway for reference biologics, the biosimilar development programs spend a great deal of time conducting analytical studies to understand the physical characteristics of the biosimilar 
Table 1 Factors increasing biologics utilization
1. Population growth
2. Increasing number of biologics available
3. Improved biologics side effects profile
a. Earlier initiation of therapy
b. Tolerating therapy longer
c. Allowing concomitant multiple lines of therapy
4. Improved efficacy
5. Improved survival rate
6. Improved survival rate
a. Longer duration of therapy
7. Improved cure rate
a. Biologic utilization on secondary and/or unrelated diseases

Table 2 Examples of analytical methods and attributes

Examples of analytical methods
- Mass spectrometry
- Peptide mapping
- Protein concentration
- Proliferative bioassay
- Fluorescence
- Edman sequencing
- Analytical ultracentrifugation
Examples of Attributes
- Amino acid sequence
- Potency
- Strength
- Receptor binding
- Molar mass
- Oxidation
- Deamidation
- Secondary and tertiary structure

molecule relative to that of the reference product (10). Table 2 shows examples of some analytical methods and attributes often examined during biosimilar development and approval process.

Once there is sufficient evidence from analytical test findings, preclinical and clinical studies are conducted; these include (PD), (PK) and immunogenicity studies. $\mathrm{PD}, \mathrm{PK}$ and immunogenicity studies can yield sufficient evidence to support biosimilarity and product approval; however, if FDA considers there is remaining uncertainly, the FDA may require additional clinical studies seeking further confirmatory evidence (11). Various studies have identified gaps in the knowledge by physicians when asked about biosimilars. This is why there is a need to increase awareness that biosimilar approvals are based on scientific data and clinical trials (5).

\section{Biosimilar indication extrapolation}

Biosimilar approval studies are designed to demonstrate "biosimilarity" in the indication with the most sensitive patient population. Through the process of extrapolation, biosimilars can be licensed for one or more additional indications of the reference biologic without the need for repeat clinical trials in each indication; however, such designation isn't automatic and is based on assessment of scientific justification for each indication (e.g., experience with the reference biologic and the totality of evidence). Scientific justification, may include, but is not limited to assessment of mechanism of action, biodistribution, and expected toxicities and immunogenicity, all relative to the different indications. As a result, extrapolation may avoid unnecessary clinical studies in all indications of the reference biologic, also helping reduce the burden on patients. Furthermore, extrapolation helps reduce sponsor's development cost, and is critical to ensure biosimilars can be marketed at the lowest viable price. This abbreviated product approval efficiency gains may also translate to more sponsor resource allocation to other areas such as research and development to help produce new innovative drugs. To date, the biosimilars FDA approvals lean toward complete or near-complete extrapolation; however, from a non-clinical perspective, it is important to recognize that active reference product patents many times hinder the biosimilars' ability to achieve complete label indications. No approved biosimilar has been denied an approvable indication based on safety and efficacy concerns as of February 2020 (4).

\section{Molecular variability or "Drift"}

Molecular variability or "drift" is expected in both reference and biosimilar biologics and product drift is not necessarily due to error. Since biologics come from living systems and not from a controlled chemical synthesis as in the case of generics, product variability is inevitable (6). All biologics are highly sensitive to many factors, including changes in manufacture and production scale. The FDA requires 
Table 3 Biosimilars approval by year

\begin{tabular}{|c|c|c|}
\hline Date of FA approval & Biosimilar product & Original medication \\
\hline April 5, 2016 & Infliximab-dyyb/Inflectra & Infliximab/Remicade \\
\hline August 30, 2016 & Etanercept-szzs/Ereizi & Etanercept/Enbrel \\
\hline September 23, 2016 & Adalimumab-atto/Amjevita & Adalimumab/Humira \\
\hline August 25, 2017 & Adalimumab-adbm/Cyltezo & Adalimumab/Humira \\
\hline September 14, 2017 & Bevacizumab-awwb/Mvasi & Bevacizumab/Avastin \\
\hline December 1, 2017 & Trastuzumab-dkst/Ogivri & Trastuzumab/Herceptin \\
\hline December 13, 2017 & Infliximab-qbtx/lxifi & Infliximab/Remicade \\
\hline July 20, 2018 & Filgastrim-aafi//Nivestym & Filgastrim//Neupogen \\
\hline October 30, 2018 & Adalimumab-adaz/Hyrimoz & Adalimumab/Humira \\
\hline November 2, 2018 & Pegfilgastrim-cbqv/Udenyca & Pegfilgastrim/Neulasta \\
\hline November 28, 2018 & Rituximab-abbs/Truxima & Rituximab/Rituxan \\
\hline December 14, 2018 & Trastuzumab-pkrb/Herzuma & Trastuzumab/Herceptin \\
\hline January 18, 2019 & Trastuzumab-dttb/Ontruzant & Trastuzumab/Herceptin \\
\hline March 11, 2019 & Trastuzumab-qyyp/Trazimera & Trastuzumab/Herceptin \\
\hline April 25, 2019 & Etanercept-ykro/Eticovo & Etanercept/Enbrel \\
\hline November 15, 2019 & Adalimumab-afzb/Abrilada & Adalimumab/Humira \\
\hline December 6, 2019 & Infliximab-axxq/Avsola & Infliximab/Remicade \\
\hline
\end{tabular}

manufactures to have a product comparability quality plan for each biologic product in order to monitor product drift over the lifecycle of each biologic drug. This monitoring plans call for routine continuous batch analyses which is compared to historical data to assess degree of variability from original compound. Biosimilar approval requires submission of analytical comparability and clinical studies that is much more extensive and in-depth compared to innovator products after production process changes post regulatory approval (4).

\section{Biologic/biosimilar differences to generics}

\section{Interchangeability}

To date, the FDA has not deemed any biosimilar interchangeable (4). If interchangeability is established for a biosimilar in the future, pharmacy substitution would 
still be subject to the individual state pharmacist drug substitution regulations. However, regulatory bodies at the institutional setting level, such as hospital's Pharmacy and Therapeutics (P\&T) Committees, can establish internal interchangeability protocols to enable independent pharmacy product substitution. To a degree, payers at the national level are treating biosimilars as interchangeable, as many have benefit designs and policies that call for substitution to either the reference or biosimilar as a preferred therapy option. In 2019, the FDA finalized its Biosimilar Interchangeability Guidelines, detailing study design and full requirements for manufacturers to pursue biosimilar interchangeability status (12). However, given existing avenues to establish internal institutional substitution protocols and given the current high level of payer autonomy on therapy preference; it is not well understood if biosimilar sponsors would be willing to invest additional resources to achieve the FDA's interchangeability designation.

\section{Post-marketing surveillance}

Pharmacovigilance is critical for all drugs to further establish their efficacy and safety profiles. With biosimilars still emerging in the U.S., it is critical to continuously assess the efficacy and safety properties of these products. Pharmacovigilance reporting is generally challenging due to the fragmented nature of the U.S. healthcare system. Pharmacovigilance reporting in the biosimilar setting introduces new challenges in terms of nomenclature and effect attribution. With new biologics and biosimilar nomenclature calling for a four letter, meaningless suffix, biosimilar reports can potentially be erroneously attributed to the reference product if the suffix is not included in the report. In addition, reports in patients using the reference and the biosimilar interchangeably can be difficult to attribute to the reference or biosimilar due to overlapping product half-life.

With the first biosimilar being introduced in the U.S. market in 2015, we benefit from an exponentially increasing amount of clinical evidence, which to date, signals a strong track record for biosimilar, as a broad category, in the U.S. and abroad. For example, to date, there is no evidence of biosimilar market removal due to efficacy or safety concerns. In addition, as more patients utilize biosimilar products, there is a growing body of real-world evidence that helps better understand long term effects and outcomes, including in extrapolation and product interchanged cases (13).

\section{Biosimilars approved by the FDA}

The FDA has approved 26 biosimilars under the Public Health Service Act covering and array of multiple medical conditions as of February 2020 (14) (Table 3). The first biosimilar approved in the U.S. was filgastrimsndz in March 2015; with the most recent approval being infliximab-azzq in December 2019. The FDA biosimilar approvals show an increasing trend as follows: 2015; one approval, 2016; three approvals, 2017; five, 2018; seven and 2019; ten new biosimilars. Currently, there are nine discrete biologics having one or more biosimilar alternative(s); those include: infliximab, adalimumab, pegfilgrastim, rituximab, bevacizumab, trastuzumab, etanercept, filgastrim, and epoetin alfa. Although almost all medications are used for malignancies or autoimmune diseases, some are used for anemia associated with kidney failure like epoetin alfa or for chemotherapy-associated low blood counts like pegfilgrastim and filgrastim (13).

Biosimilar development, approval, ability to market and practice implementation has become so debated, that the American Society of Clinical Oncology (ASCO) has opened their own Biosimilars Work Group to provide guidance on how to evaluate biosimilar available clinical evidence and how to effectively and safely integrate in practice (15). In contrast to the United States, the European Healthcare system has been approving biosimilar products for longer, achieving significantly greater number of product approvals, higher product discounts and market penetration. The more stringent US patent laws, along with rebating practices as well as having an Average Selling Price (ASP)-dependent reimbursement system are partly responsible for the slower uptake of biosimilars in the US.

Biosimilars are not granted patent exclusivity, which allows multiple pharmaceutical companies to pursue biosimilar approval and production. For example, what this has translated to in real up-to-date practice in breast cancer patients is six biosimilars FDA-approved for trastuzumab, followed by adalimumab:five, anfliximab:four and pegfilgastrim:three biosimilars (14).

As more biosimilars receive regulatory approval and reach the market, it will be increasingly important for healthcare providers to understand how biosimilars are developed and approved, in order for them to gain trust in their effectiveness and safety $(3,5,11,12)$. The increasing 
aging population along with improvements in diagnosis tests for malignancies call for continued increased demand of biologics. Lastly, there is now over a decade of real-world evidence showing a good biosimilar track record, including utilization in extrapolated indications.

\section{Conclusions}

Overall healthcare cost continues to rise in the US with biologics being in the highest spend drug category. The ending of full patent exclusivity period for some biologic drugs presents opportunities to increase market competition in the space. Today, a variety of biosimilars have been approved and marketed in the US, offering discounts ranging from $25-40 \%$ compared to the corresponding reference product. Making lower cost medication alternatives available may serve as a release valve to the unsustainable, yet continuously increasing healthcare spend trend. Although biosimilars have proven a strong safety record and value proposition that is well aligned with the evolution of payment models, the biosimilar industry still faces many challenges to product development, approval, market and practice implementation. Healthcare professionals need to stay committed to the evaluation of biosimilar evidence to make this treatment option available where there is evidence supporting product biosimilarity.

\section{Acknowledgments}

Funding: None.

\section{Footnote}

Reporting Checklist: The authors have completed the Narrative Review reporting checklist. Available at http:// dx.doi.org/10.21037/tlcr-20-601

Conflicts of Interest: All authors have completed the ICMJE uniform disclosure form (available at http://dx.doi. org/10.21037/tlcr-20-601). LR receives research support from: Amgen, BMS, Merck, Roche, Genentech, AstraZeneca, Pfizer, Novartis, Syndax and Loxo. The other authors have no conflicts of interest to declare.

Ethical Statement: The authors are accountable for all aspects of the work in ensuring that questions related to the accuracy or integrity of any part of the work are appropriately investigated and resolved.
Open Access Statement: This is an Open Access article distributed in accordance with the Creative Commons Attribution-NonCommercial-NoDerivs 4.0 International License (CC BY-NC-ND 4.0), which permits the noncommercial replication and distribution of the article with the strict proviso that no changes or edits are made and the original work is properly cited (including links to both the formal publication through the relevant DOI and the license). See: https://creativecommons.org/licenses/by-nc-nd/4.0/.

\section{References}

1. Ledón N, Lage A. Biosimilars and the Real World. MEDICC Rev 2017;19:9.

2. Kaida-Yip F, Deshpande K, Saran T, et al. Biosimilars: Review of current applications, obstacles, and their future in medicine. World J Clin Cases 2018;6:161-6.

3. Cazap E, Jacobs I, McBride A, et al. Global Acceptance of Biosimilars: Importance of Regulatory Consistency, Education, and Trust. Oncologist 2018;23:1188-98.

4. Sullivan PM, DiGrazia LM. Analytic characterization of biosimilars. Am J Health Syst Pharm 2017;74:568-79.

5. Cohen H, Beydoun D, Chien D, et al. Awareness, Knowledge, and Perceptions of Biosimilars Among Specialty Physicians. Adv Ther 2017;33:2160-72.

6. Nabhan C, Valley A, Feinberg BA. Barriers to Oncology Biosimilars Uptake in the United States. Oncologist 2018;23:1261-5.

7. Azevedo V, Dörner T, Strohal R, et al. Considerations for Clinical Practice. Available online: https://considerations. bmj.com/content/1/1/13

8. Konstantinidou S, Papaspiliou A, Kokkotou E. Current and future roles of biosimilars in oncology practice. Oncol Lett 2020;19:45-51.

9. Coiffier B. Preparing for a new generation of biologic therapies: understanding the development and potential of biosimilar cancer therapeutics. Future Oncol 2017;13:1-3.

10. Mehr SR, Brook RA. Factors influencing the economics of biosimilars in the US. J Med Econ 2017;20:1268-71.

11. The State of Biosimilars in 2019. Managed Healthcare Executive. Accessed June 29, 2020. Available online: https://www.managedhealthcareexecutive.com/view/statebiosimilars-2019

12. Considerations in Demonstrating Interchangeability With a Reference Product Guidance for Industry. Available online: https://www.fda.gov/regulatory-information/ search-fda-guidance-documents/considerationsdemonstrating-interchangeability-reference-product- 
guidance-industry

13. Lyman GH, Zon R, Harvey RD, et al. Rationale, Opportunities, and Reality of Biosimilar Medications. N Engl J Med 2018;378:2036-44.

14. Research $\mathrm{C}$ for DE and. Biosimilar Product Information. FDA. Published online June 11, 2020. Accessed June
29, 2020. Available online: https://www.fda.gov/drugs/ biosimilars/biosimilar-product-information

15. Lyman GH, Balaban E, Diaz M, et al. American Society of Clinical Oncology Statement: Biosimilars in Oncology. J Clin Oncol 2018;36:1260-5.

Cite this article as: García JJ, Raez LE, Rosas D. A narrative review of biosimilars: a continued journey from the scientific evidence to practice implementation. Transl Lung Cancer Res 2020;9(5):2113-2119. doi: 10.21037/tlcr-20-601 